\title{
Regulatory Practices that Impact Viable Quality Health Care
}

\section{Patricia A. Seabrooks}

Department of Nursing, Miami Regional University, 700 S Royal Poinciana Blvd Suite 100, Miami Springs, FL 33166, United States.

Article Details
Article Type: Commentary
Received date: $03^{\text {rd }}$ October, 2019
Accepted date: $16^{\text {th }}$ October, 2019
Published date: $18^{\text {th }}$ October, 2019

*Corresponding Author: Patricia A. Seabrooks, Department of Nursing, Miami Regional University, 700 S Royal Poinciana Blvd Suite 100, Miami Springs, FL 33166, United States. E-mail: pseabrooks@mru.edu

Citation: Seabrooks PA (2019) Regulatory practices that impact viable quality health care. J Comp Nurs Res Care 4: 148. doi: https://doi.org/10.33790/jenrc1100148.

Copyright: (C2019, This is an open-access article distributed under the terms of the Creative Commons Attribution License 4.0, which permits unrestricted use, distribution, and reproduction in any medium, provided the original author and source are credited.

\begin{abstract}
"Nursing education consists of the theoretical and practical experience provided with the purpose to prepare nurses for duties as health care professionals. This education is provided to nursing students by educated and experienced nurses and other medical professionals who have qualified or experienced for these educational tasks. During past decades, (the) changes in education have replaced the more practically focused, but often ritualistic, training structure of conventional preparation."
\end{abstract}

Today, nursing education integrates a broader awareness of other disciplines allied to medicine, often involving inter-professional education, and the utilization of research when making clinical and managerial decisions.

The impact and goal of nursing education is to develop a confident, inquiring graduate who contributes to the care team as an equal and provides safe competent care to the clients for whom they have responsibility.

The educational process must have the capability to achieve the expected and desired outcomes for the profession. Incorporating pedagogical techniques across nursing courses to create an "impactful" learning experience, faculty must encourage the development of a curriculum and clinical experiences that will keep students motivated and interested.

The Association of American Colleges and Universities published an overview of High Impact Educational Practices which included the following:

Suggestions for student engagement and ultimately student retention:

- Seminars and small group experiences

- Required common courses and group experiences

- Establishment of learning communities made up of liberal arts and nursing courses.

- Writing intensive assignments in all nursing courses from the beginning.

- Collaborative assignments and projects which encourage the development of listening skills and insights into the others' thoughts and ideas.

- Undergraduate research or projects that require a semblance of research, to involve students in asking questions, observing systematic solving problems using investigation and technology.
The research projects could begin early in the student's courses and become their "signature" work. Signature work develops cumulatively over the trajectory of the courses in the program. Signature work might include multiple disciplines and faculty involvement to the degree that students are able to apply their learning in meaningful ways.

"When students are motivated to learn, they build and develop skills that employers need and the graduates are ready for the market when they graduate."

"In nursing education, which is a practice discipline, the education is complicated; one can use the clients' first entry into the health care system as a basis for teaching and learning. Primary care, also the first point of entry, is an approach that:“

- Focuses on the person not the disease, considers all determinants of health

- Integrates care when there is more than one problem

- Uses resources to narrow differences

\section{Components of Primary Health Care (PHC)}

- Education concerning prevailing health problems and the methods of preventing and controlling them Promotion of food supply and proper nutrition

- An adequate supply of safe water and basic sanitation

- Maternal and child health care including Family Practice

- Health Education

- Expanded Program of Immunization

- Safe water and Sanitation

- Control of Endemic Diseases

- Provision of Essential Drugs

- Strategies of Primary Health Care

1. Reducing excess mortality of poor marginalized populations:

PHC must ensure access to health services for the most disadvantaged populations and focus on interventions which will directly impact on the major causes of mortality, morbidity and disability for those populations.

\section{Reducing the leading risk factors to human health:}

PHC, through its preventative and health promotion roles, must address those known risk factors, which are the major determinants of health outcomes for local populations.

\section{Developing Sustainable Health Systems:}

PHC as a component of health systems must develop in ways, which 
are financially sustainable, supported by political leaders, and supported by the populations served.

4. Developing an enabling policy and institutional environment:

PHC policy must be integrated with other policy domains and play its part in the pursuit of wider social, economic, environmental and development policy.

Examples of High Impact Strategies: Seminars, intensive writing, collaborative projects, internships, learning communities, undergraduate research.

Creating healthcare professionals by using high Impact teaching and Learning practices

Impactful education of health care professionals is a practical solution to the health professional manpower shortage in diverse high usage areas. There are many educated and experienced physicians and other health care workers who migrate to other countries for various reasons. Bringing those professionals out of the shadows to re-training them to provide a new level of health care to the areas in the community or within the global society where there is a need will enhance the health of many who would not have access otherwise.

It will also encourage the foreign trained health care professionals to provide the type of quality care that they intended to practice in their home countries. Health care education and practice have many duplicate courses and skills across health care professionals' training. Communities can use the duplication as a jump start for retraining and re-educating the professional at a different level to provide care to a community where there is a need. Regulatory practices are critical to determine that the public is protected and that individuals who practice a profession are skilled and competent within an identified scope of practice within the healthcare profession.

\section{Advanced Practice nurses from impactful experiences and education}

Educating and training foreign trained physicians or other professional health therapists to become professional nurses and/or advanced practice nurses provide a successful method to populate the health professional manpower shortage areas. These skilled professionals tend to learn the art and science of nursing, particularly the skills, at a rapid pace. It takes longer to change attitudes and behaviors related to the theories related to nursing practice and the limitations on the scope of practice of advanced practice when the new student in nursing was once the "captain" of the ship and wrote the "orders" for nurses to follow.

\section{Practicing Advanced Practice nurse from foreign trained medical doctor}

New nurses must realize that nursing is its own profession and works with other health care professionals to provide the quality care that the clients deserve and expect. There are several programs for foreign-trained physicians (FTP's) in the US. It is common that the students in these nursing programs believe that they do not really need the education, just the license. However, when asked nursing questions or when testing on nursing content, they do no perform well. It does not take long for the motivated FTP to accept the idea of "thinking like a nurse" in order to experience success in the course work and on the national examinations. Faculty and managers must take into consideration that the scope of practice for professional nursing and advanced practice nursing maybe unknown to these new professionals. The curriculum should be designed to focus on the desired health care outcomes for the program and then work on the student level expected course outcomes.

Regulations, scope of practice and certification (after NCLEX)

- Laws that bind: Statutes and Rules

- Testing and Passing: State and National Exams

- Licensing and Certification: State and National credentials

- Protecting the Public: Consequences for unprofessional behavior
- Providing Health Care to the Public

Conflict of interest: The authors declare no conflict of interest.

\section{References}

1. Local, State and Regional Nursing Practice Regulations.

2. Eynon, B, Gambino, L.M. (2017) High impact e-portfolio practice, in Bradshaw M.J. and Hultquist, B.L., Innovative Teaching Strategies in Nursing and related health professions, Google Books 2019.

3. Kitson, A, Marshall A, Bassett K, Zeitz K (2012) What are the core elements of patient-centered care? 